\title{
Design and Simulation of a Fused Silica Space Cell Culture and Observation Cavity with Microfluidic and Temperature Controlling
}

\author{
Shangchun Fan, ${ }^{1,2,3}$ Jinhao Sun, ${ }^{1,2,3}$ Weiwei Xing, ${ }^{1,2,3}$ Cheng Li, ${ }^{1,2,3}$ and Dongxue Wang ${ }^{1,2,3}$ \\ ${ }^{1}$ School of Instrument Science and Opto-Electronics Engineering, Beihang University, 37 Xueyuan Road, Haidian District, \\ Beijing 100191, China \\ ${ }^{2}$ Key Laboratory of Precision Opto-Mechatronics Technology, Ministry of Education, Beihang University, Beijing 100191, China \\ ${ }^{3}$ Key Laboratory of Inertial Science and Technology for National Defence, Beihang University, Beijing 100191, China
}

Correspondence should be addressed to Jinhao Sun; maomao9242@163.com

Received 11 June 2013; Accepted 27 September 2013

Academic Editor: Bo Yu

Copyright (C) 2013 Shangchun Fan et al. This is an open access article distributed under the Creative Commons Attribution License, which permits unrestricted use, distribution, and reproduction in any medium, provided the original work is properly cited.

\begin{abstract}
We report a principle prototype of space animal cell perfusion culture and observation. Unlike previous work, our cell culture system cannot only realize microfluidic and temperature controlling, automatic observation, and recording but also meet an increasing cell culture at large scale operation and overcome shear force for animal cells. A key component in the system is ingenious structural fused silica cell culture cavity with the wedge-shaped connection. Finite volume method (FVM) is applied to calculate its multipoint flow field, pressure field, axial velocity, tangential velocity, and radial velocity. In order to provide appropriate flow rate, temperature, and shear force for space animal cell culture, a closed-loop microfluidic circuit and proportional, integrating, and differentiation (PID) algorithm are employed. This paper also illustrates system architecture and operating method of the principle prototype. The dynamic culture, autofocus observation, and recording of M763 cells are performed successfully within $72 \mathrm{~h}$ in the laboratory environment. This research can provide a reference for space flight mission that carries an apparatus with similar functions.
\end{abstract}

\section{Introduction}

The increasing demand of recombinant therapeutic proteins, monoclonal antibodies, and vaccines produced by mammalian cells has stimulated the development of space cell culture technology, for which almost all space powers have a huge interest. In order to make an in-depth research of space cell culture characteristics, some space powers have developed various space cell culture devices [1-4]. Many of these have completed space flight mission that are shown in Table 1 and Figure 1. Such space cell culture apparatus not only provides appropriate temperature, adequate nutrition and oxygen, low concentration of toxic secretions, and reasonable mechanical property but also records details of cell proliferation [5]. However, space perfusion cultures require more efficient and advanced system, the most frequently reported based on microfluidic chip with kinds of sensors [610] and aerospace heat transfer [11]. Rotating wall bioreactor is widely used because the internal spin-filters are conducive to perfusion rates and reproductive rate at large-scale operation $[12,13]$. In this case, the defects such as high energy consumption, noise, low space utilization, and shear force have been considered as limitation of culture duration and process performance.

Despite the great importance of cell culture data after space flight, many studies have been carried out mainly to recognize the differences between original ground data before space flight experiment and new character after it. These studies apparently cannot meet the current research requirements today $[14,15]$. Early efforts indicate that microfluidic technology plays an important role in large-scale cell operation, real-time observation, and recording. Dynamical culture in space biological experiments becomes increasingly needed [16, 17]. Dynamical culture can ensure that cells always get enough fresh nutrient solution and metabolic waste is moved out during culture process and construct 
TABLE 1: Space cell culture instruments development at home and abroad.

\begin{tabular}{|c|c|c|c|}
\hline Name & Country & Flight plan & Time \\
\hline Woodlawn wanderer-9 & US & Salyut-3 & 1978 \\
\hline Biotherm & Switzerland & Salyut-4; Salyut-5 & 1982 \\
\hline Cytos I & France & Salyut-6 & 1982 \\
\hline Biorack & Germany & D-1 & 1983 \\
\hline Carry-on & Switzerland & STS-8 & 1984 \\
\hline Cytos II & France & Salyut-7 & 1986 \\
\hline Dynamic cell culture system & Switzerland & IML-1 & 1988 \\
\hline Static training device & China & Jian-yi-yi satellite & 1989 \\
\hline Cell culture device & Japan & IML-2 & 1994 \\
\hline Improved CCS & China & Jian-yi-yi satellite & 1994 \\
\hline Miniature space cell culture device (SBRI) & Switzerland & STS-65; S/MM-03 & 1994 \\
\hline Cell culture device & China & Shen Zhou 3 & 2002 \\
\hline
\end{tabular}

a more suitable environment for long-term cell culture. Furthermore, compared with the conventional cell culture techniques [18], the combination of microfluidic chip and cell culture techniques will benefit long-term cell culture and improve cell biology research levels. However, only a certain aspect but not the complete system is introduced in the majority of reports in this field, not to mention considering the impact of the acceleration of gravity.

The study presented in this paper involves fused silica cell culture cavity's simulation, design, and perfusion experiment, which is carried out under realistic operating conditions of temperature and flow rate, using M763 cells. With a wedgeshaped connection, the newly designed cavity is free from the effects of gravitational acceleration before entering orbit and is better sealed. Fused silica is adopted for its outstanding optical property, insulating property, thermal conductivity, and stability, all of which enable the cavity to be isolated from harsh outside environment. In this paper, firstly the creatively designed cavity structure, simulation, and experimental verification of microflow FVM are presented. Then a description of hardware circuits and software design is given. At last, a complete space cell system is conducted and characteristics are listed. The research has some theoretical and engineering value on the design and implementation of space cell culture system.

\section{Materials and Methods}

Our automatic guided space cell culture system mainly includes cell culture unit, observation and record unit, and intelligent control unit; still all outer space conditions need to be overcome. In the outer space, the equipment is expected to executive automatically operations presetted. The experimental apparatus for cell perfusion simulations is shown in Figure 2.

2.1. Design and Fabrication of the Cavity. Entire cell culture cavity adopts fused silica, which has the following advantages: perfect thermal stability, low deformation, resistance to high acid and contamination, high hardness, and excellent light transmittance.
Cell culture cavity (Figure 3 ) is mainly made up of two parts: the upper cover and the lower cover. The upper and the lower covers are pressed together to form a hollow cell culture cavity. Cell suspension and reagent and metabolic waste go in and out through the three wedge-shaped cylindrical pipes welded to the lower cover. Both the upper and the lower covers have $50 \mathrm{~mm}$ diameter circular photic zone; the rest part is made as matte at roughness 3.2 and fastened via eight through-bolts in uniform distribution. The upper cover, lower cover, micro pressure sensor cavity, and three wedgeshaped catheters are shown in the assembly drawing of cell culture cavity (Figure 4).

To make the structure better sealed, the three wedgeshaped cylindrical pipes in the lower cover and three independent catheters are connected to micro pressure sensor cavity through the wedge connection, which contributes to overcoming the overload when entering orbit. Using Polytetrafluoroethylene (PTFE) tube connects inlet and outset into a rotary value, and then the rotary valve is connected to micropump, thus making it easy for the system to control micro fluid. The pipe in between serves as a waste export as well as a biochemical detection port. The overall structural design is ingenious and highly modularized.

The system allows automatically real-time observation and recording in dynamical culture process through circular photic zone, which facilitates light irradiation and benefits the microscopic observation. The practical parameters of cell culture cavity are shown in Figure 5. Heating coil (Figure 6) is designed in lower cover surface to provide a suitable temperature.

What matters most in this experiment is how to design a perfect cell culture cavity and locate it precisely. A threedimensional servo platform with high precision is designed to cooperate with microscopic observation. The top of the servo platform is the fixed device of cell culture cavity (Figure 7).

2.2. The Theory of the Computational Fluid Dynamics. Continuous equation, namely, the conversation of mass equation, means that any liquidity issue must agree with the law of conversation of mass. In accordance with the law of conversation of mass, the sum of the fluid rest mass out of 


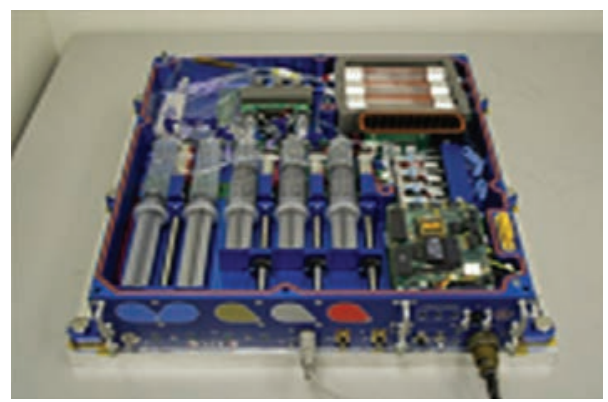

(a) ESA/CSA cooperation of unmanned Foton M3 task tray of cell culture

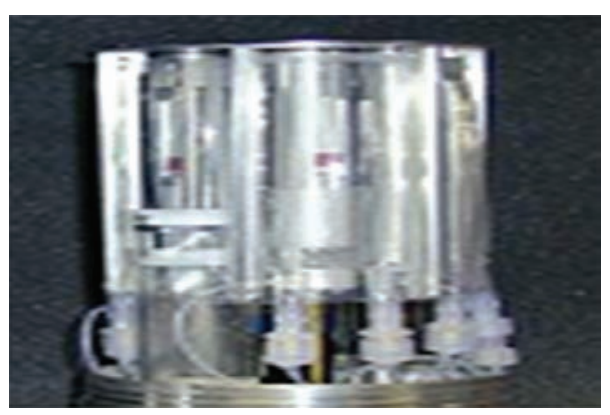

(c) NASA BioServe culture device

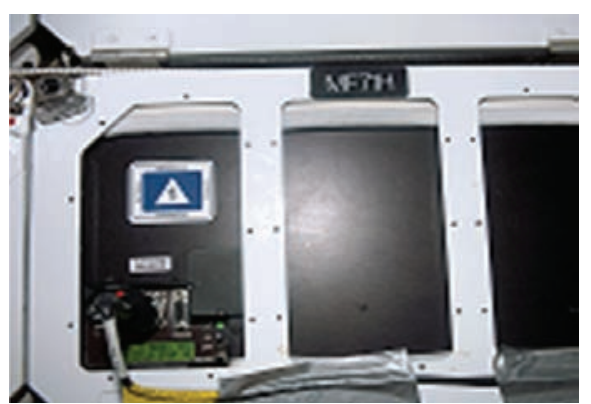

(b) NASA BTS cells culture module, for the space station

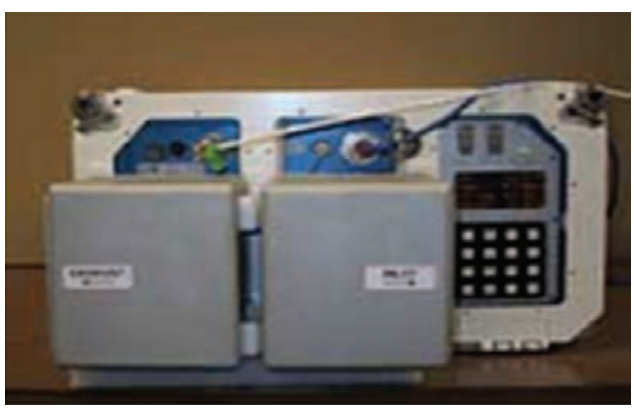

(d) NASA-CGBA

FIGURE 1: Successful applications of space cell culture instruments.

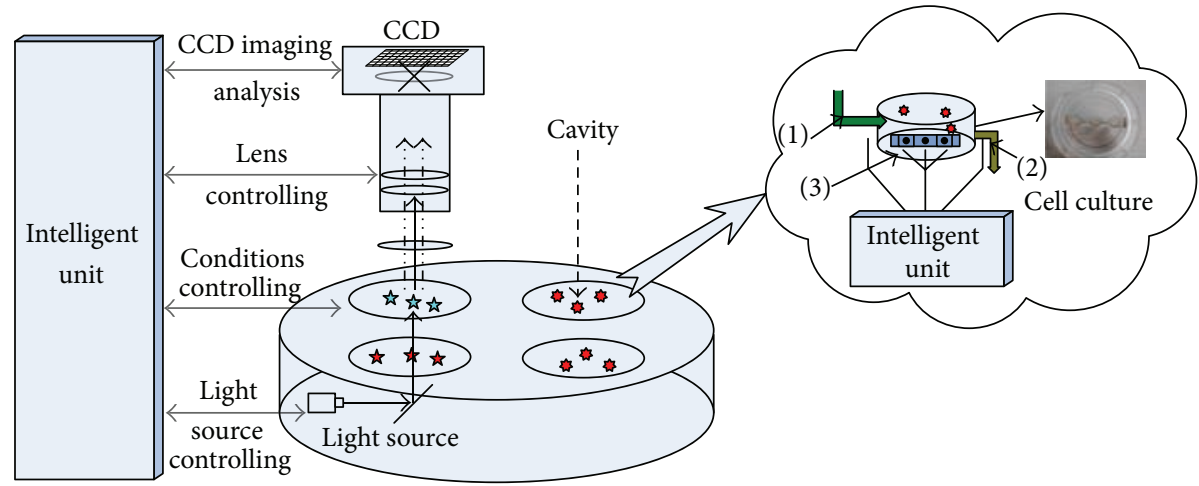
(1) Inlet
(2) Waste
(3) Outlet

FIGURE 2: Experimental set-up for cell perfusion simulations.

control interval in unit time should be equal to the reducing quality caused by density variations in control interval in the same unit time. Based on that, the differential form of fluid flow continuous equation can be derived as

$$
\frac{\partial \rho}{\partial t}+\frac{\partial\left(\rho u_{x}\right)}{\partial x}+\frac{\partial\left(\rho u_{y}\right)}{\partial y}+\frac{\partial\left(\rho u_{z}\right)}{\partial z}=0,
$$

where $u_{x}, u_{y}$, and $u_{z}$ are, respectively, the component of velocity $(\mathrm{m} / \mathrm{s})$ for three directions, $t$ is time $(\mathrm{s})$, and $\rho$ is density $\left(\mathrm{kg} / \mathrm{m}^{3}\right)$.
The Hamiltonian differential operator is derived

$$
\nabla=i \frac{\partial}{\partial x}+j \frac{\partial}{\partial y}+k \frac{\partial}{\partial z}
$$

Equation (1) can be expressed as (3) and divergence form (4):

$$
\begin{aligned}
& \frac{\partial \rho}{\partial t}+\nabla \cdot(\rho \vec{u})=0, \\
& \frac{\partial \rho}{\partial t}+\operatorname{div}(\rho \vec{u})=0 .
\end{aligned}
$$




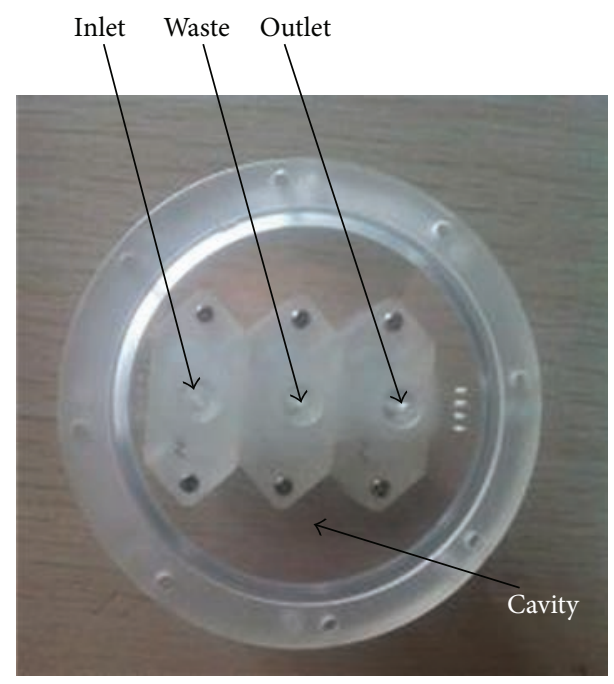

FIgURE 3: A photograph of cell culture cavity.

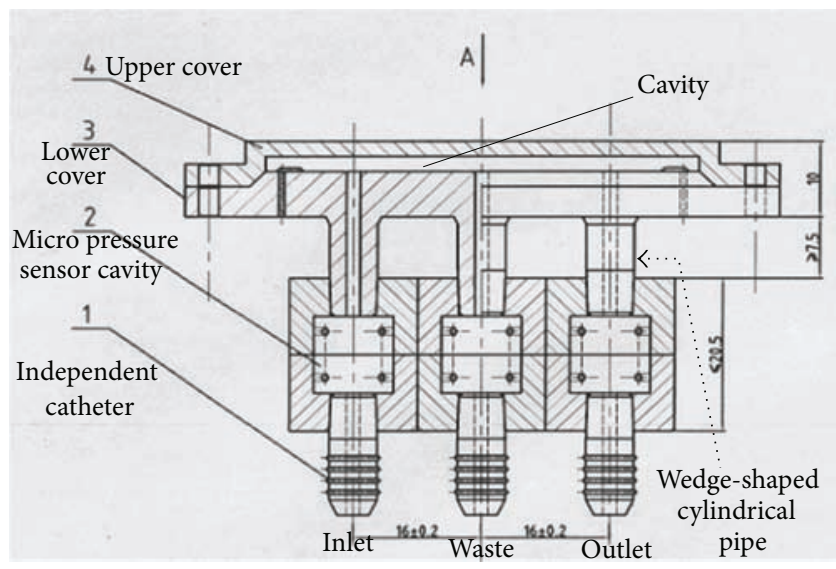

FIgURE 4: The assembly drawing of cell culture cavity.

The form of the continuity equation is expressed as (5) in a cylindrical coordinate system:

$$
\frac{\partial \rho}{\partial t}+\frac{\rho u_{r}}{r}+\frac{\partial\left(\rho u_{r}\right)}{\partial r}+\frac{\partial\left(\rho u_{\theta}\right)}{r \partial \theta}+\frac{\partial\left(\rho u_{z}\right)}{\partial z}=0 .
$$

Equation (5) is the normal continuity equation for general use. If for steady flow $\partial \rho / \partial t=0$, its form should be changed to

$$
\frac{\partial\left(\rho u_{x}\right)}{\partial x}+\frac{\partial\left(\rho u_{y}\right)}{\partial y}+\frac{\partial\left(\rho u_{z}\right)}{\partial z}=0
$$

For incompressible flow, in the flow process, the density $\rho$ of each dot is always unchanged, that is, $\partial \rho / \partial t=0$ and $\rho \neq 0$; the form of the continuity equation of incompressible fluid can be derived as

$$
\frac{\partial u_{x}}{\partial x}+\frac{\partial u_{y}}{\partial y}+\frac{\partial u_{z}}{\partial z}=0
$$

Cylindrical coordinate's form of (7) is

$$
\frac{u_{r}}{r}+\frac{\partial u_{r}}{\partial r}+\frac{\partial u_{\theta}}{r \partial \theta}+\frac{\partial u_{z}}{\partial z}=0
$$

The motion equation of viscous fluid was first proposed in 1827 by Navier who only took the flow of incompressible fluid into account. Poisson proposed the equation of the compressible fluid in 1831. Saint-Venant and Stokes, respectively, in 1843 and 1845, independently proposed the form in which viscosity coefficient was a constant, now known as NavierStokes equation, referred to as the N-S equation.

For incompressible viscous fluid, the N-S equation is

$$
\frac{\partial \vec{u}}{\partial t}+(\vec{u} \cdot \nabla) \vec{u}=f-\frac{1}{\rho} \nabla p+\frac{\mu}{\rho} \nabla^{2} \vec{u} .
$$

In (9), $\vec{u}$ (vector symbol) represents velocity $(\mathrm{m} / \mathrm{s}), p$ represents pressure $(\mathrm{Pa}), \mu$ represents the viscosity of fluid $\left(\mathrm{kg} / \mathrm{m}^{3}\right)$, and the pressure gradient $\nabla p$ is expressed as and

$$
\nabla p=i \frac{\partial p}{\partial x}+j \frac{\partial p}{\partial y}+k \frac{\partial p}{\partial z}
$$

$\nabla^{2}$ in (9) is Laplacian operator described as (11). The left part of (9) represents the inertia force; in the right part, they represent inturn mass force, pressure (or pressure gradient), and the viscous force:

$$
\nabla^{2}=\frac{\partial^{2}}{\partial x^{2}}+\frac{\partial^{2}}{\partial y^{2}}+\frac{\partial^{2}}{\partial z^{2}},
$$

N-S equation accurately describes the actual flow. Viscous fluid flow analysis usually refers to researching N-S equation. Because of its rather complex form, only a handful can find the exact solution. The study of numerical solving is usually applied. N-S equation is also the basic equation for calculating the computational fluid dynamics. It can be said that all flow problems revolve around solving N-S equation.

2.3. Perfusion Numerical Simulations. According to the animal cells growth requirements, we need to endow micro fluid in the cell cavity with low shear force, good transmission effect, and so on. The truth is that there are always some mutual restraint factors among these principles. For example, a fully hybrid environment is required to strengthen its transmission effect during the dynamical culture process, while the vulnerability of animal cells restrict the formation of such an environment. Therefore theoretical analysis on the nature of the fluid mechanics of the design structure is carried out to optimize the constraints among the above-mentioned principles. The authors in [19] indicate that apart from some simple cases, it is difficult to give analytical solution to the most fluid mechanics problems, so computational fluid dynamics (CFD) is adopted in their analysis.

In a calculation of CFD, the cell suspension is usually regarded as incompressible and homogeneous Newtonian fluid so that Turbulent Navier-Stokes mathematical model is applied to solve [20]. Reynolds number represents the ratio 


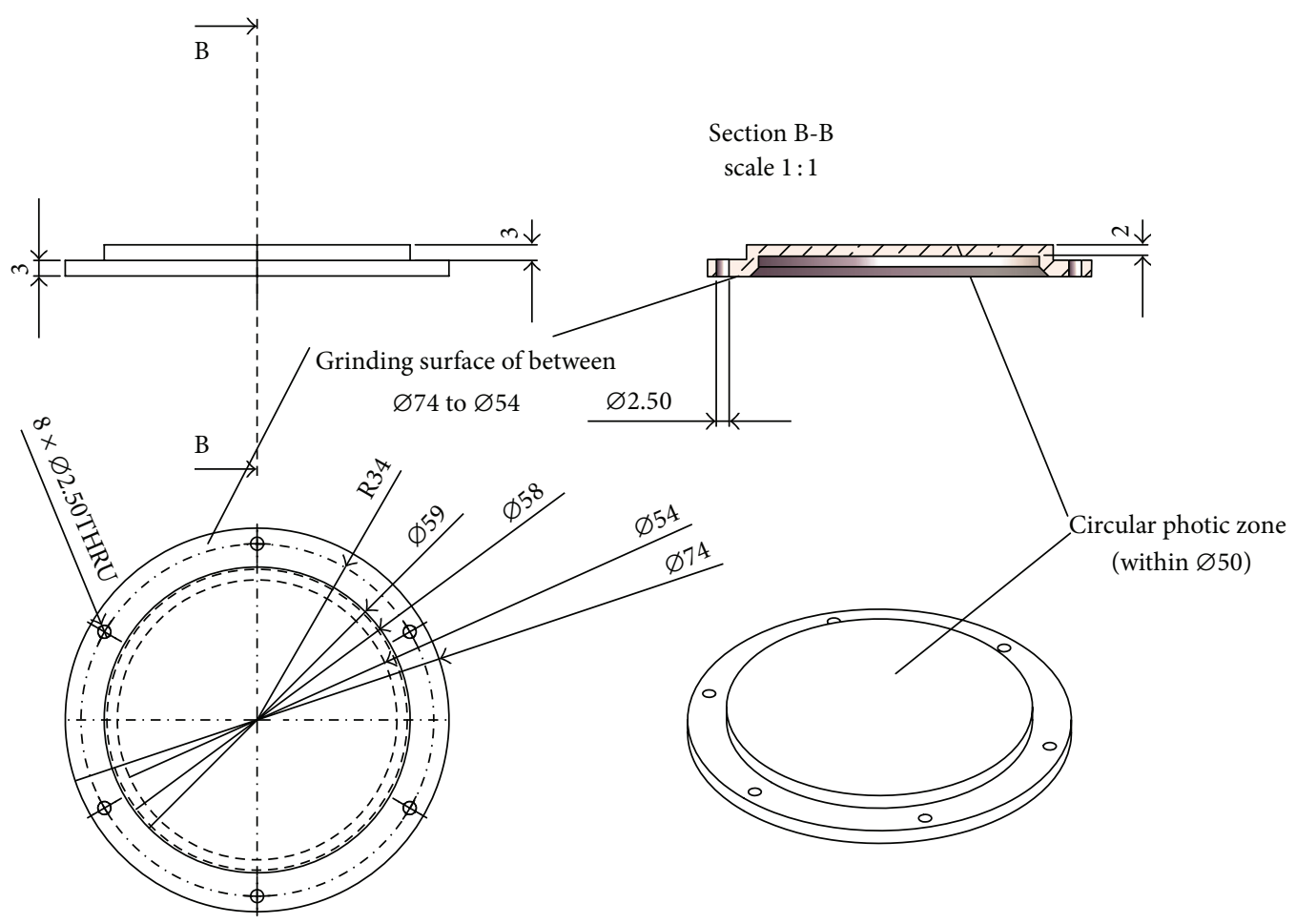

FIGURE 5: The engineering drawing for upper cover of cell culture cavity.

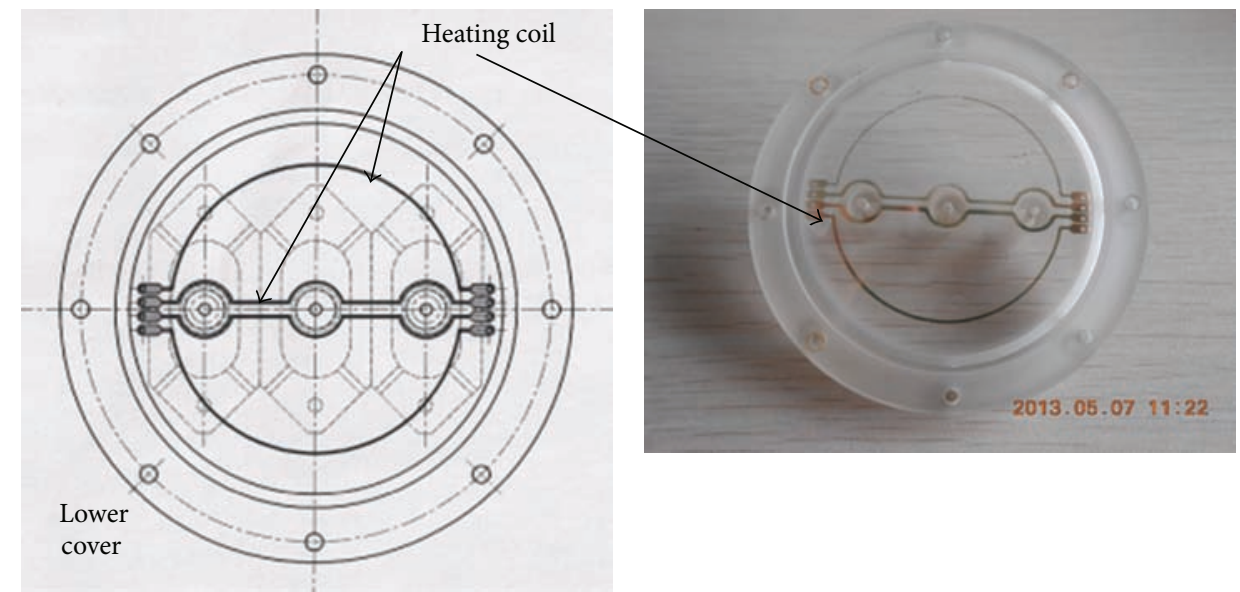

FIGURE 6: The engineering drawing for lower cover of cell culture cavity.

of fluid inertial force of unit mass and viscous force, discriminating the laminar and turbulent flow. Since Reynolds number in microfluidic scale is relatively smaller than 0.01 $(\operatorname{Re}<0.01)$, the pressure-driven flow through the cell culture unit is laminar flow [21]. Reynolds number can be calculated by

$$
\operatorname{Re}=\frac{\rho V d}{\mu},
$$

where $V$ stands for the average flow rate, $d$ is equal to characteristic length, also equal to hydraulic diameter, and then equal to 4 multiplies by overcurrent cross-sectional area divided by wetted perimeter. The relationship between the flow velocity and flow rate in working fluid inlet port is described as

$$
v=\frac{w}{A},
$$

where $v$ stands for flow rate, $w$ is the inlet flow, and $A$ is the cross-sectional area of the micro channel.

We check the validity of the number of grids. We perform numerical simulation for five different grids at 604160, 791808, 946096, 1144500, and 1529928, respectively, with same inlet total pressures. We have the curve result of the flow rate for outlet total pressure loss as shown in Figure 8(b). Three curves of grid nodes at 946096,1144500 and 1529928 


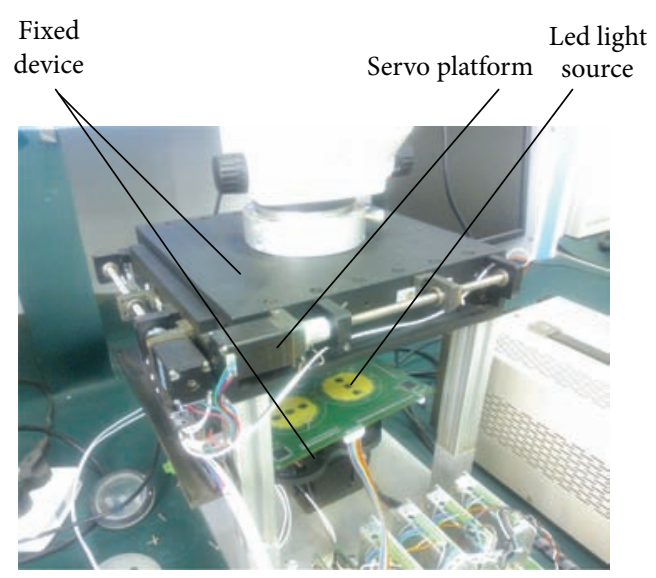

FIGURE 7: A photograph of cell culture cavity three-dimensional servo platform.

were almost overlapped, as could be seen in Figure 8(b). Thus it is demonstrated that the flow field is independent of the number of grids when the grid nodes are greater than or equal to 946096 . Finally, the 1144500 grid nodes are applied, and that is in line with grid independency.

Based on the above discussion, "Numeca" software and Fine-solver are adopted in the simulation. Finite volume method (FVM) is employed to study flow and pressure distribution of micro fluid during perfusion in the microfluidic cell culture cavity. The streamline field and pressure field distribution in the cell culture cavity under different flow velocity and inlet static pressure are calculated by applying Numeca simulation analysis software. The height of the cell culture cavity is $2 \mathrm{~mm}$, diameter $50 \mathrm{~mm}$, and volume $15,708 \mathrm{~mm}^{3}$. The diameter of the fluid inlet and fluid outlet pipes is $1.7 \mathrm{~mm}$. During establishing a physical mesh this cavity is divided into 1,144,500 griddings as shown in Figure 8, among which 1,020,285 grid nodes are used for cavity and 41,405 grid nodes for inlet and outlet pipes. We also increase the density of the solid wall mesh, and the mesh width of first layer is $0.001 \mathrm{~mm}$. For the convenience of calculation, the material parameters of the working fluid adopt the material parameters of water (density at $998.3 \mathrm{~kg} / \mathrm{m}^{3}$; the viscosity at $\left.1.003 \times 10^{-3} \mathrm{~kg} /(\mathrm{m} \cdot \mathrm{s})\right)$. Apart from inlet and outlet, the rest of cavity is seen as the solid wall boundaries of adiabatic and no-slip boundary. Firstly, simulation of large flow under the temperature at $15^{\circ} \mathrm{C}$ is carried out at inlet total pressures of $110,000,120,000$, and $150,000 \mathrm{~Pa}$ and the outlet static pressure is 101,000 Pa. The result is as shown in Figure 9. At the same time the simulation of the condition in greater pressure and larger flow rate is carried out and the result is shown in Figure 10.

The results indicate that when the outlet static pressure and temperature keep unchanged, the flow correlates with pressure: total inlet pressure of $110,000 \mathrm{~Pa}$ corresponds to flow rate of $2.791 \mathrm{~g} / \mathrm{s}, 120,000 \mathrm{~Pa}$ corresponds to $5.279 \mathrm{~g} / \mathrm{s}$, $150,000 \mathrm{~Pa}$ corresponds to $10.03 \mathrm{~g} / \mathrm{s}$, and 200,000 Pa corresponds to $15.31 \mathrm{~g} / \mathrm{s}$. Secondly, the other things being equal, a simulation analysis at the flow rate $200 \mathrm{mg} / \mathrm{s}$ is carried out again. It can be seen from Figure 11 that both the

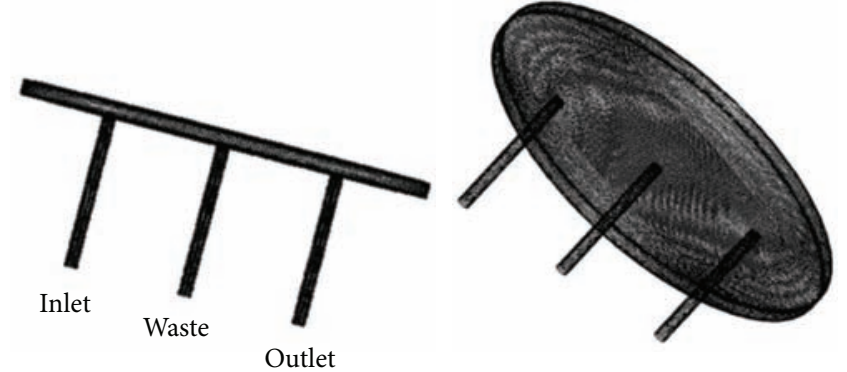

(a)

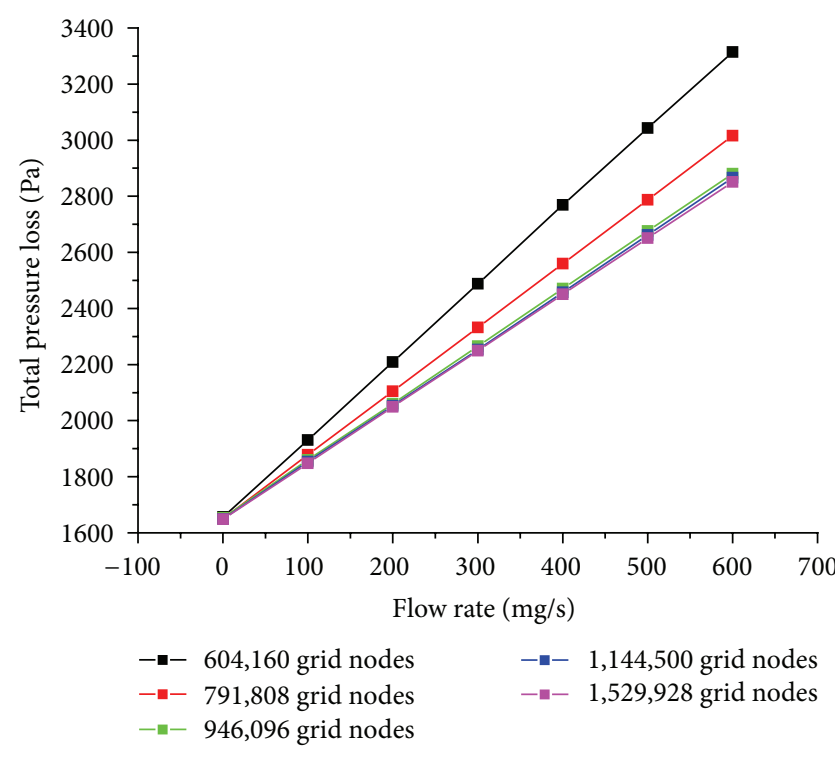

(b)

Figure 8: The grids method: (a) the side view of mesh division for cell culture internal cavity, (b) the curve result of the flow rate for outlet total pressure loss.

pressure field and the streamline field meet the requirements. Finally, the micro flow simulation result is shown in Figure 12.

It can be seen from the streamline distribution graph (Figure 9) that ejection happens in both of the two entrances. The differential pressure (or flow rate) is so great that the fluid injects to the inner wall of the upper cover. Obviously, this is against the protection of the cell structure, because the well-distributed streamline field means establishment of the cycle process of dynamical culture. It can be seen from the middle surface pressure filed distribution (Figure 10(a)) that the max differential pressure value in the cell culture cavity is $2000 \mathrm{~Pa}$, which is too great to be conducive to cell culture. When the flow rate is $2 \times 10^{-4} \mathrm{~kg} / \mathrm{s}$, the max differential pressure value is only $12 \mathrm{~Pa}$ (Figure $10(\mathrm{~b})$ ) and the pressure field in the cavity is well distributed. Sharp change on differential pressure only happens in the fluid inlet and outlet. This meets the requirements. It can be seen, from the streamline distributions (Figures 12(b), 12(c), 12(d)), that there is no infinite loop in the whole cavity area. Infinite loop emerges in the cell cavity when the flow rate is $3 \times 10^{-7} \mathrm{~kg} / \mathrm{s}$ 


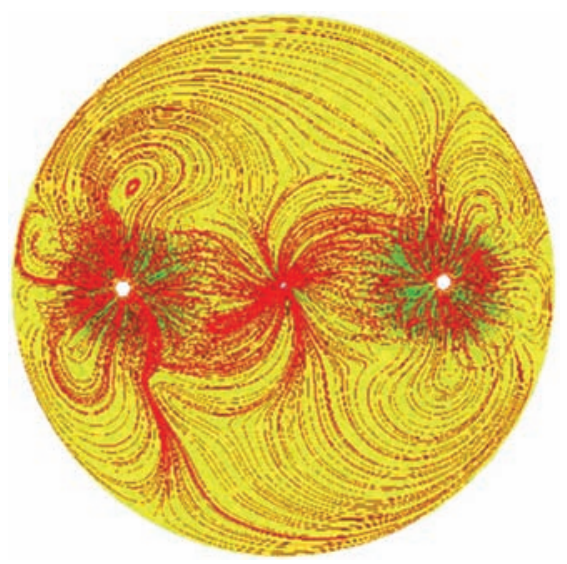

(a)

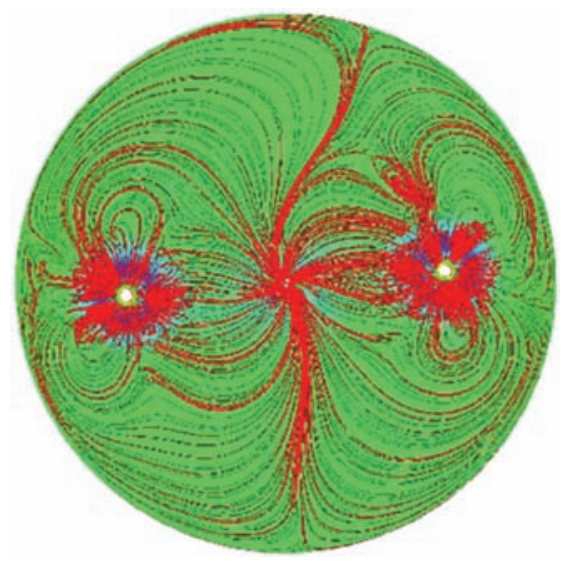

(c)
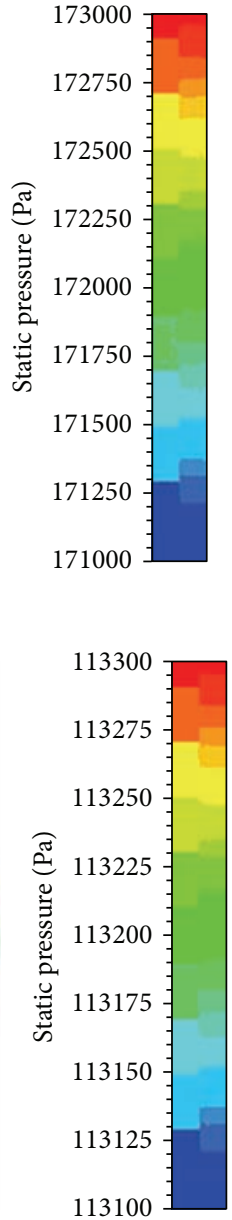

113100

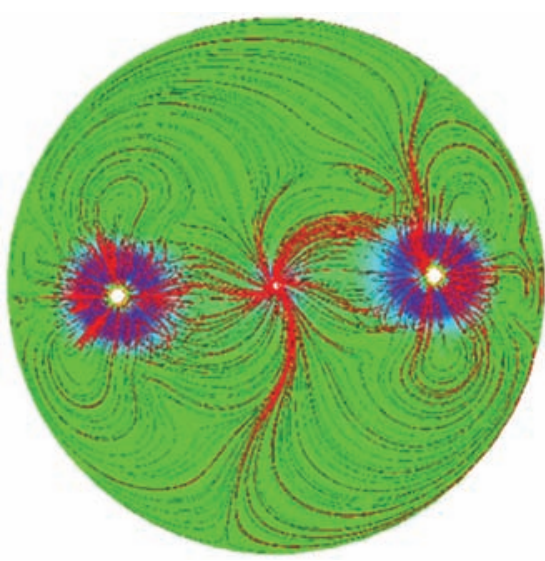

(b)

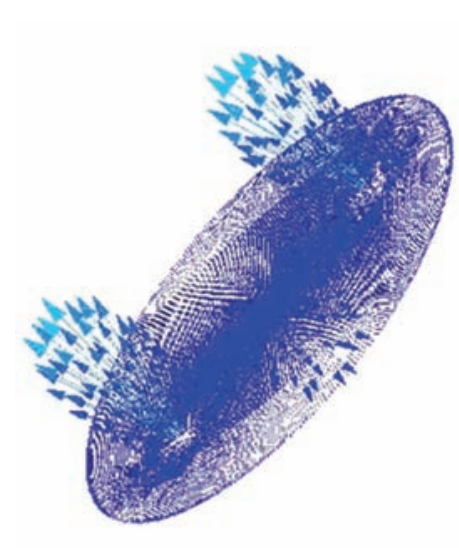

(d)
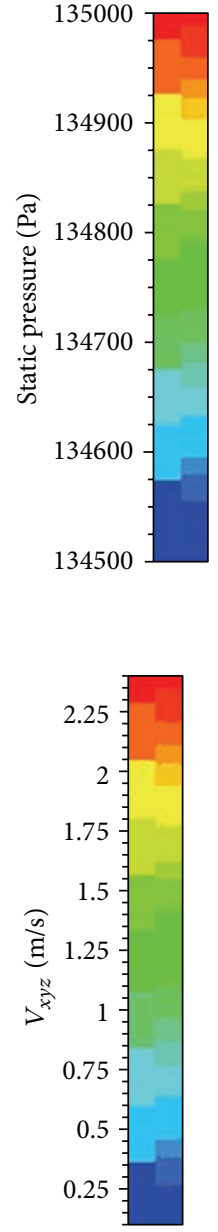

Figure 9: The simulation results in large flow: (a) the middle surface streamline chart in inlet static pressure of 200,000 Pa, (b) the middle surface streamline chart in inlet static pressure of $150,000 \mathrm{~Pa}$, (c) the middle surface streamline chart in inlet static pressure of $120,000 \mathrm{~Pa}$, (d) the middle surface vector of cavity in inlet static pressure of $150,000 \mathrm{~Pa}$.

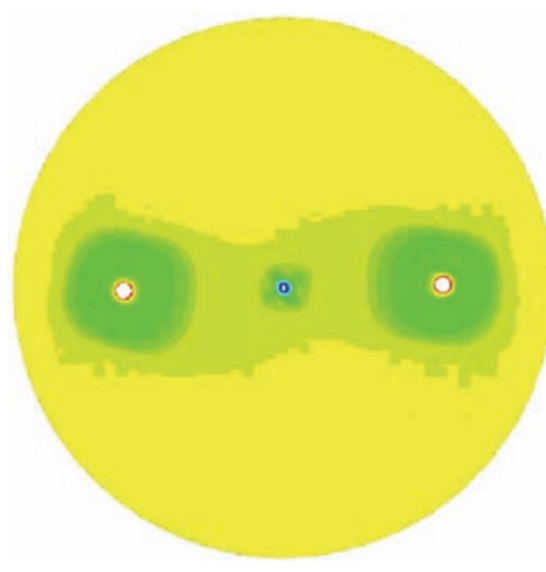

(a)
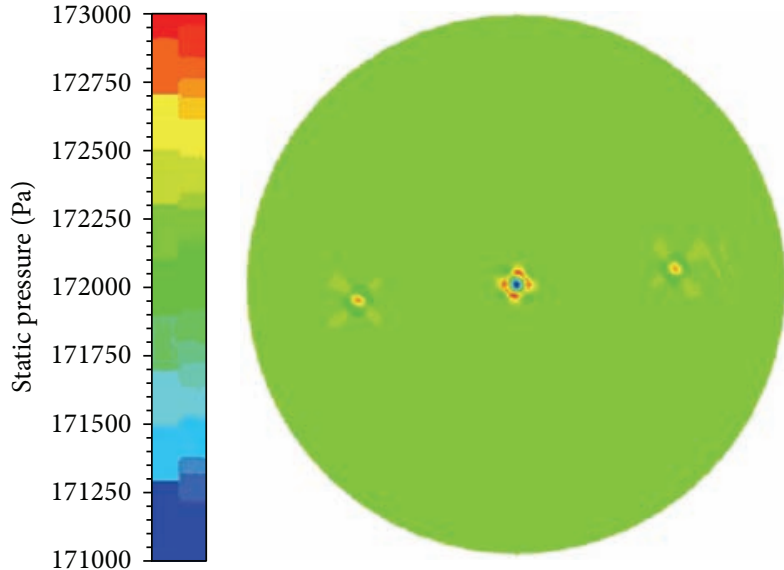

(b)

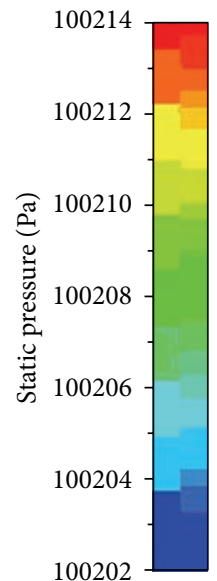

FIGURE 10: The pressure distribution graph of cell culture cavity: (a) the middle surface pressure distribution graph in inlet static pressure of $200,000 \mathrm{~Pa}$, (b) the pressure field distribution when the flow rate is $2 \times 10^{-4} \mathrm{~kg} / \mathrm{s}$. 


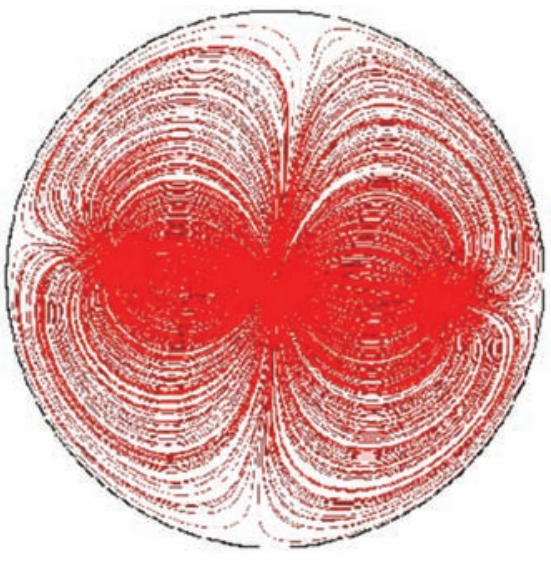

(a)

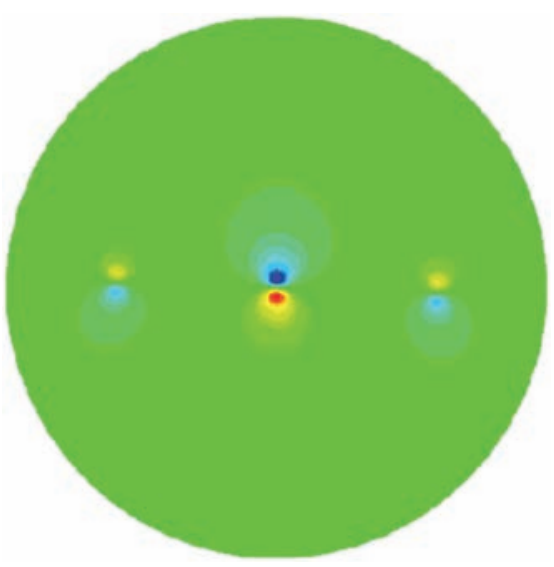

(c)
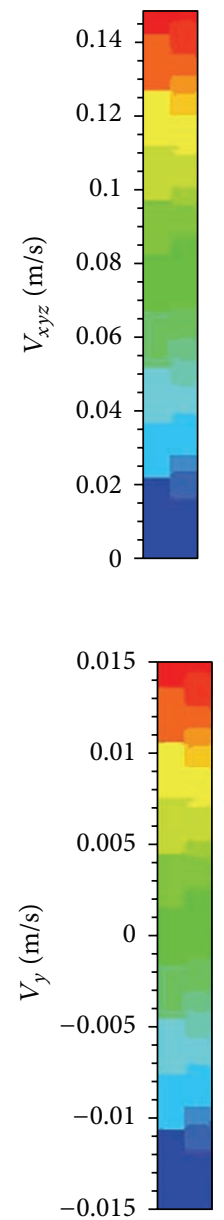

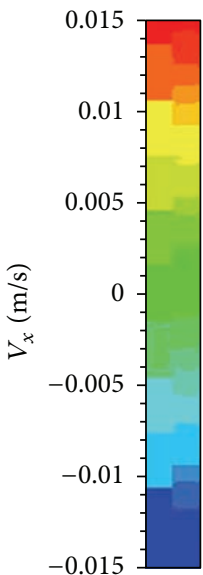

(b)
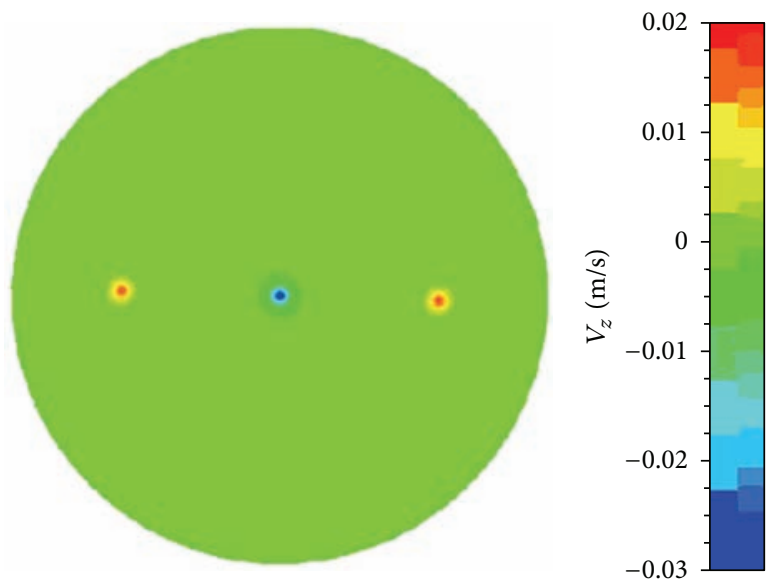

(d)

FIGURE 11: The simulation analysis when the flow rate is $200 \mathrm{mg} / \mathrm{s}$. (a) Streamline distribution, (b) velocity distribution in $x$ direction, (c) velocity distribution in $y$ direction, (d) velocity distribution in $z$ direction.

(Figure 12(a)) and there is hardly pressure difference, which is regarded as the minimum flow rate of the designed cavity. Of course, further calibration is supposed to be in line with the actual experimental environment and the overall equipment characteristics.

The different cell culture and experimental design demand different flow rate, for they have different cell culture volumes and different days in culture. Based on the experimental experience, the simulation of the feature points sampling is carried out to work out the maximum value and the minimum value, thus estimating the flow rate control range. So we roughly select the minimum of flow rate, that is, $3 \times 10^{-7} \mathrm{~kg} / \mathrm{s}$, and the maximum of flow rate $200 \mathrm{mg} / \mathrm{s}$ according to the animal cells growth requirements. The result of Numeca analysis software also identifies that the structure design program of cell culture cavity is reasonable and the flow field is well distributed.

2.4. Experimental Device for Perfusion Cell Culture. Automatic guided space cell culture system aims to realize unattended cell culture, observation, and recording with microfluidic and temperature control circuits. This system involves high-speed analog signal synchronous sampling technique, embedded technology, intelligent power technology, servo control technology, multisensors information fusion, dedicated bus technology, SCADA technology, microfluidic hardware and software technology, and intelligence analysis technique. Major circuit diagram is shown in Figure 13 consisting of Synchronous differential pressure sampling circuit, controller area network (CAN) and RS485 bus circuit, embedded control board, cell culture circuit, PCI-104 data acquisition module, the serial port expansion module, and processing analysis software. Cell culture and the extended port in the back panel of observation platform are as shown in Figure 14. These ports are mainly used to connect microscope, motor, and multisensor circuit board. As is shown in Figure 15, the multisensor data is used to acquire sampling unit pressure, temperature, biochemical parameter, and lighting control; the motor with CAN bus and RS232 port is used to control valve and micropump. The microscope of observation system has three grating rulers to control displacement in three directions. When we want to 


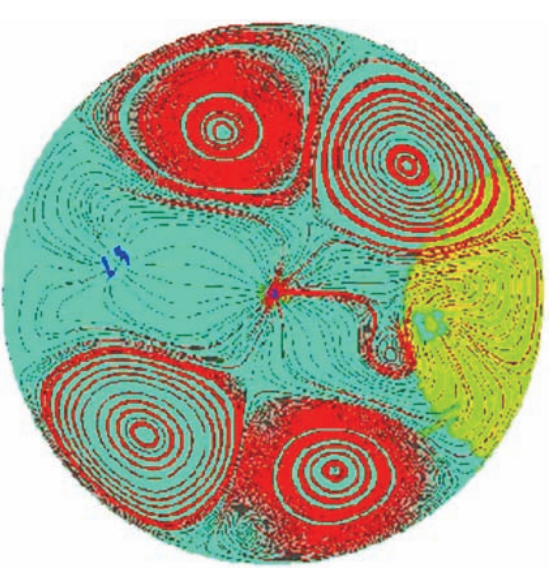

(a)

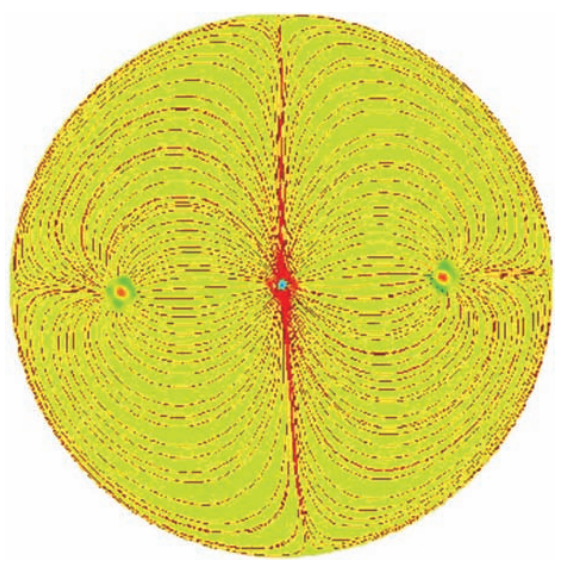

(c)
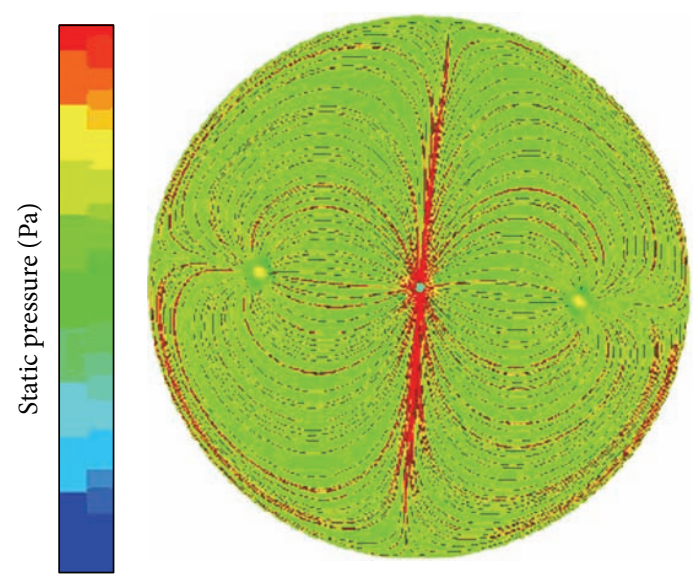

(b)
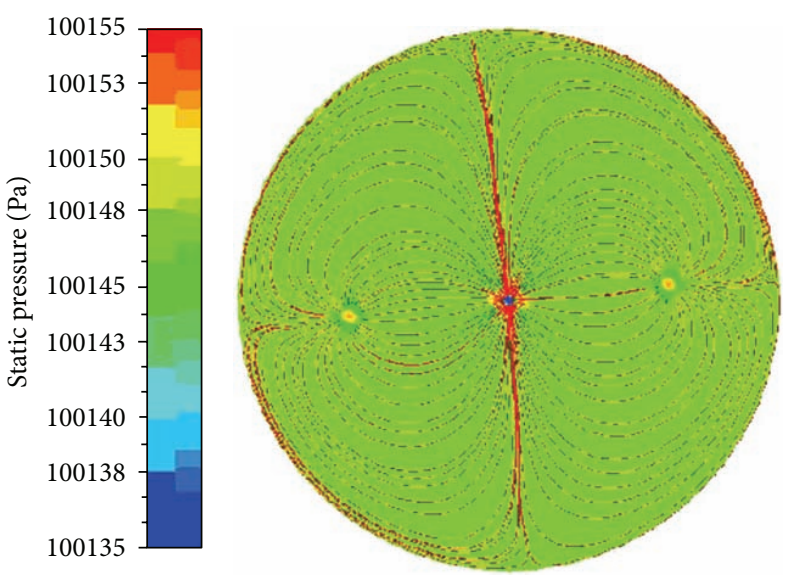

(d)
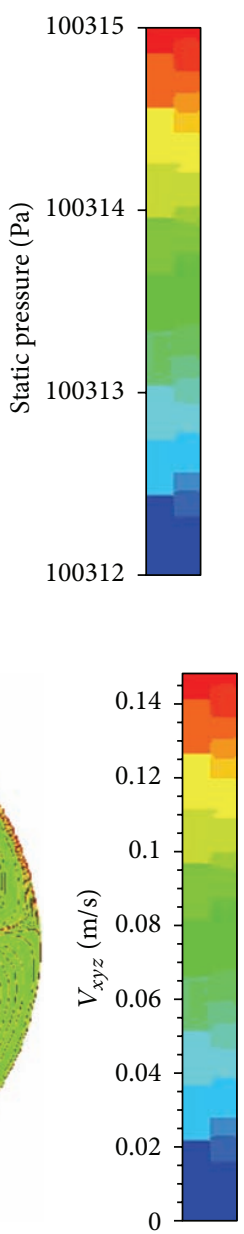

FIGURE 12: The simulation results of micro flow: (a) the flow field distribution when the flow rate is $3 \times 10^{-7} \mathrm{~kg} / \mathrm{s}$, (b) the flow field distribution when the flow rate is $3 \times 10^{-5} \mathrm{~kg} / \mathrm{s}$, (c) the flow field distribution when the flow rate is $3 \times 10^{-4} \mathrm{~kg} / \mathrm{s}$, (d) the flow field distribution when the flow rate is $2 \times 10^{-7} \mathrm{~kg} / \mathrm{s}$.

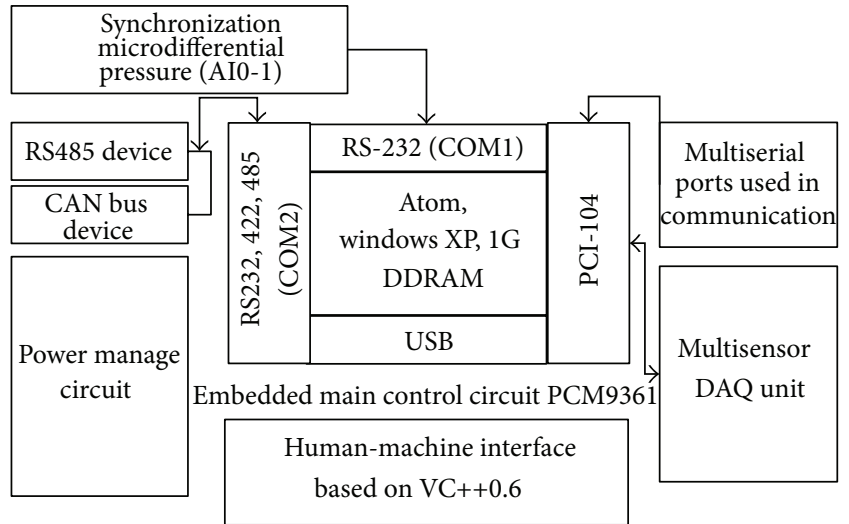

FIGURE 13: Cell culture and observation system platform diagram.

move over a direction for a certain distance, the servo motor powers it. The grating rulers acquire RS232 outputs pulse to calculate the precise displacement location, so that the microscope performs autofocus observation, other direction way similar. The communication between cell culture and observation system platform and microscope observation system uses three RS232 serial ports for the displacement controlling in $x, y$, and $z$ directions and one USB port for the transmission of image data. Moreover, the micro pump closed-loop controlling of microfluidic system needs pressure sensor sampling value and two motors with RS232 and CAN. According to the simulation results and discussion of cell culture cavity, the microfluidic software flow chart is designed as shown in Figure 16. Temperature controlling system consists of temperature sensor PT100, micro controller C8051F, heating coil, and so on. and adopts PID algorithm. It adjusts the cavity temperature to cell culture.

The human-machine interaction interface of cell culture and observation system platform adopts a 10.5 inch touch screen and then fixes it on the front panel of cabinet. Microsoft Visual C++ is adopted for its software programming. 


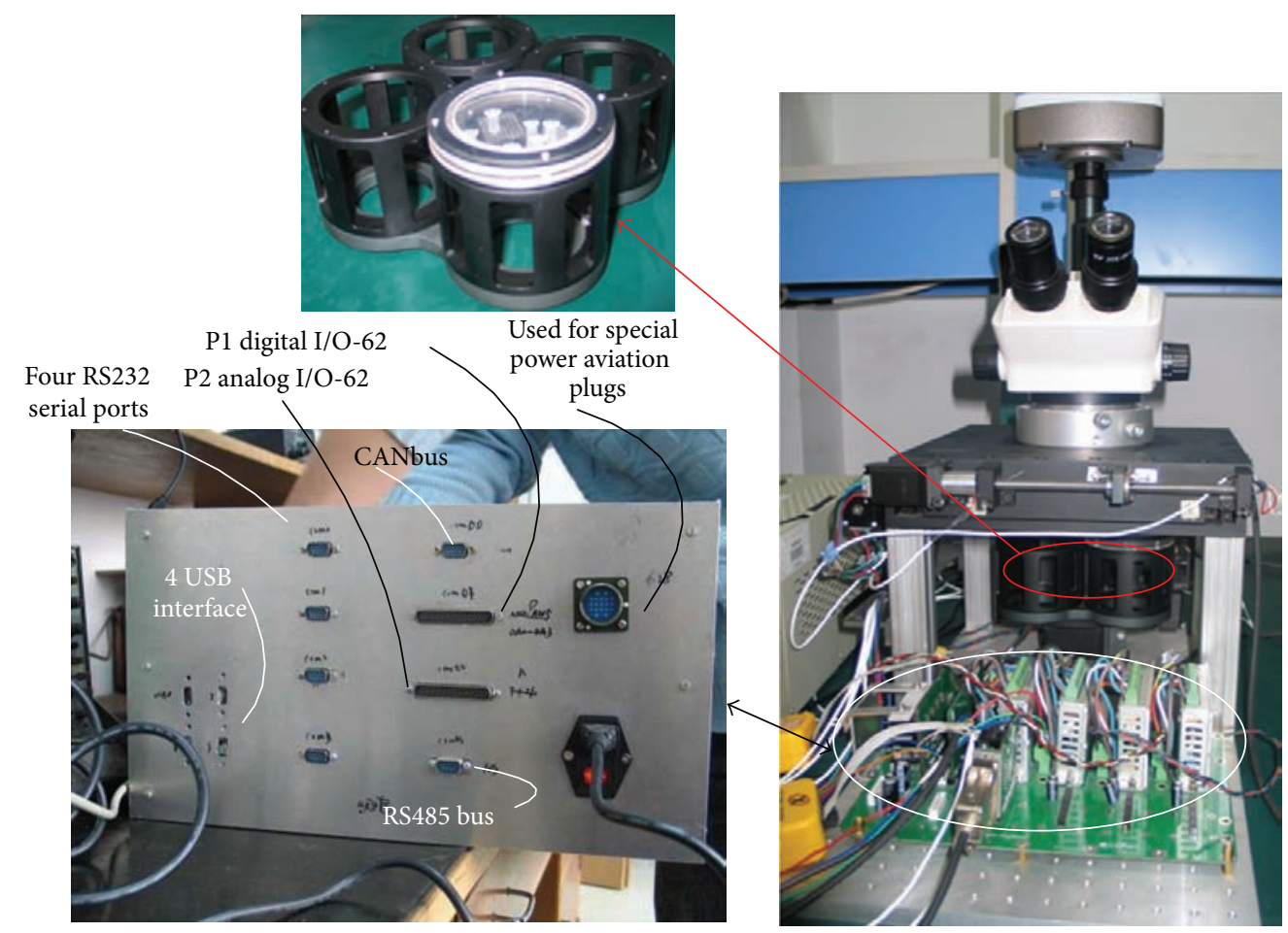

FIGURE 14: A photograph of cell culture and observation system platform.

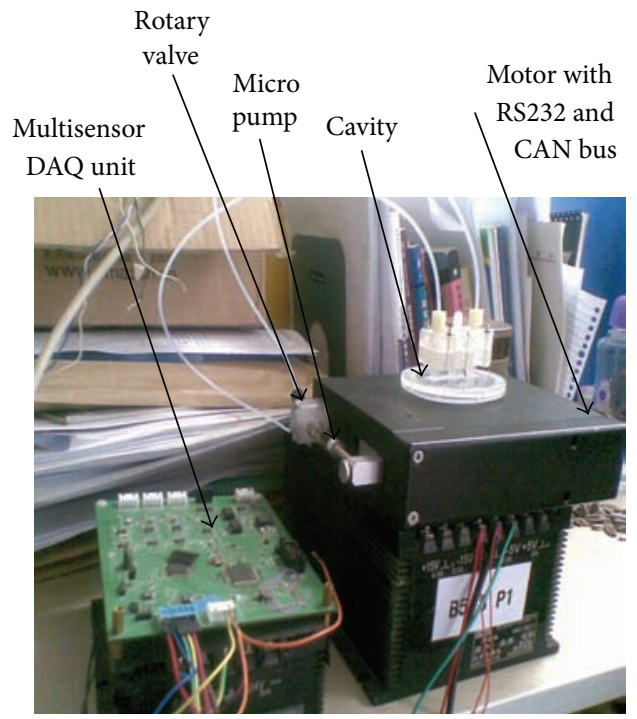

FIGURE 15: A photograph of micro pump and multisensor data acquisition unit.

\section{Results and Discussion}

In the present system, the cell's requirement for nutrients and dissolved oxygen is met by the replacement of the culture medium in the cell culture cavity. When the flow rate is too large, it will not only cause the waste of the culture medium, but also the shear force and vortex that is bad for cells. The determination of the flow rate mainly relates to nutrients and dissolved oxygen supply and shear force. The supply of nutrients and dissolved oxygen is estimated empirically according to the required culture solution replacement time, which mainly depends on the structure and capacity of the culture vessel and cell type. The size of the shear force is related to the size of the flow rate as well as the structure of the culture vessel. Therefore, the flow rate of the culture solution is first estimated empirically according to required replacement time, and then we calculate whether the shear force caused by the flow rate meets the requirements. The appropriate flow rate is ultimately determined by experiment. Since M763 cells are cultured at $36.5 \pm 0.5^{\circ} \mathrm{C}$, temperature controlling circuits are expected to perform with a highspeed response and in a permitted error range. Adhering to the distance metering principle, traditional focusing technology mainly employs the distance system to drive the lens to find the best observation location, while this method needs additional equipment. Considering that space flight mission asks the equipment to be as small and light as possible, the initiative technology is employed. This technology uses image information to analyze focus direction and adjust the focal length to the best position. Since the focusing quality is decided by algorithm of the initiative technology [22], we adopt the morphological wavelet decomposition pyramid for microscopy system autofocusing.

3.1. Measurements. Two experiments are carried out on the temperature control unit and the result shows that the temperature of the cavity can be stabled. In experiment 1 , the initial temperature is set as $27.68^{\circ} \mathrm{C}$, the target temperature as $36.5^{\circ} \mathrm{C}$, and temperature rising curve is as shown in Figure 17. 

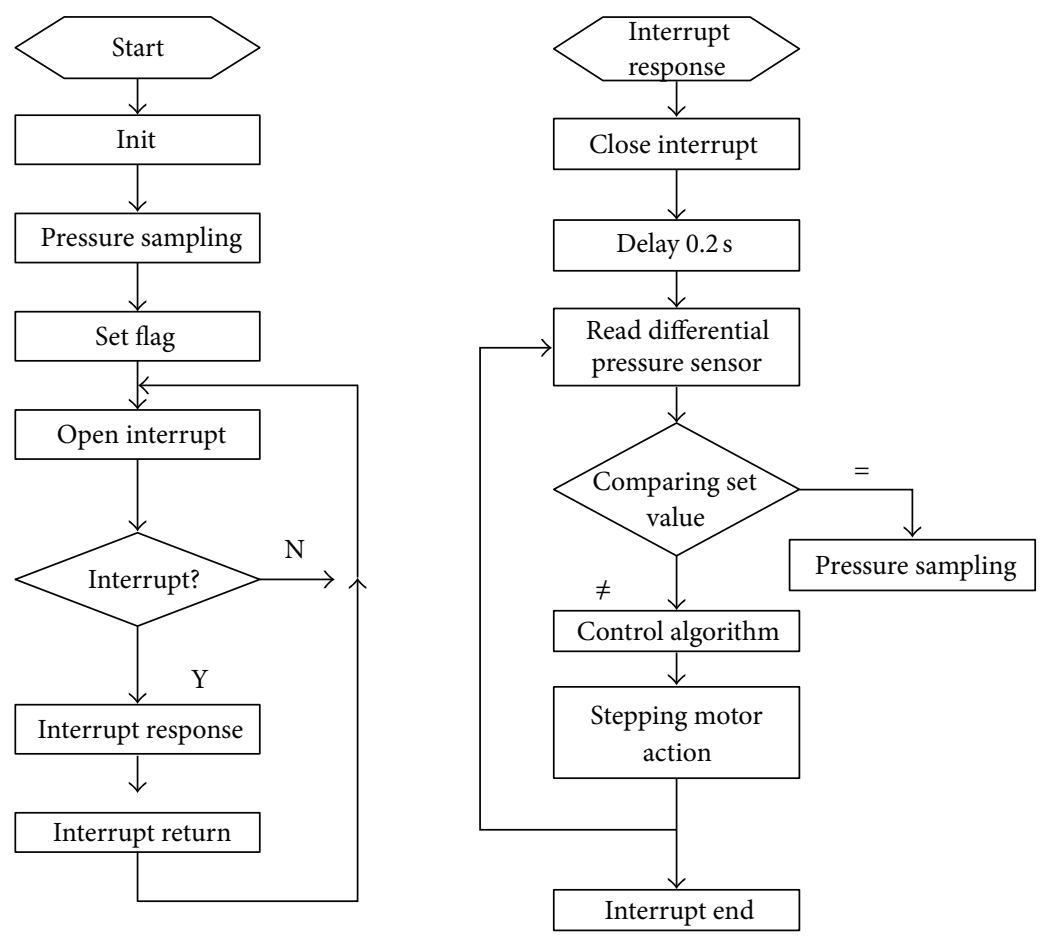

FIGURE 16: Micro fluid controlling software flow chart.

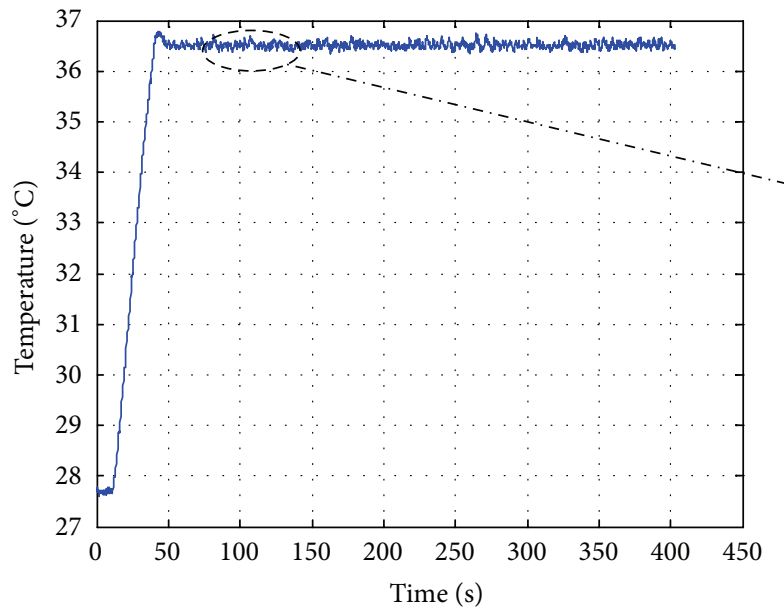

(a)

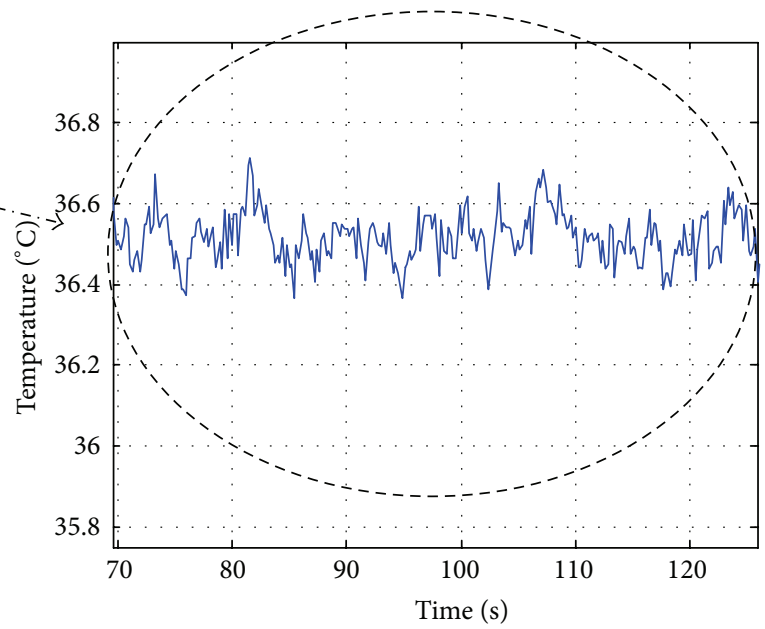

(b)

Figure 17: (a) Temperature characteristic of temperature closed-loop control circuit with start temperature at $27.68^{\circ} \mathrm{C}$. (b) Temperature characteristic partial enlarged detail.

It can be seen that the time from the initial temperature to the target temperature is about $38 \mathrm{~s}$ and the temperature error is in the range of $\pm 0.5^{\circ} \mathrm{C}$. In experiment 2, the initial temperature is set as $31.65^{\circ} \mathrm{C}$, the target temperature $36.5^{\circ} \mathrm{C}$, temperature rising curve is as shown in Figure 18. it can be seen that the temperature remains stable after $25 \mathrm{~s}$, so it is concluded that the rising of environmental temperature leads to the reduction of rising time. 72-hours-cell culture and observation are carried out with the aid of the culture cavity. Microscope (Nikon ECLIPSE TiS, Nikon Corporation, Japan), CCD (Olympus), and the cell culture and observation system platform form a cell image observation system. Figure 19 is the growth records of M763 in the cavity captured by the image observation system. We can see that the cells in 24 hours, have stuck to the wall and unfolded completely. In 48 hours, apparent cell division 


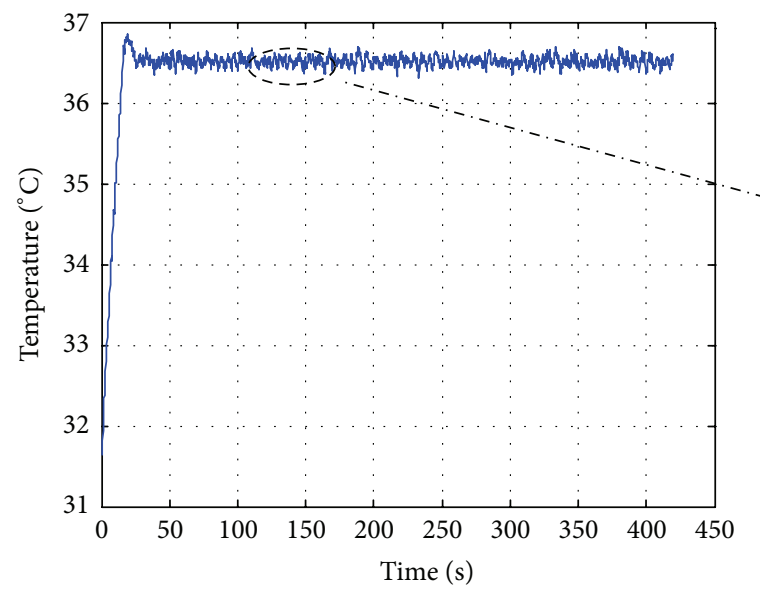

(a)

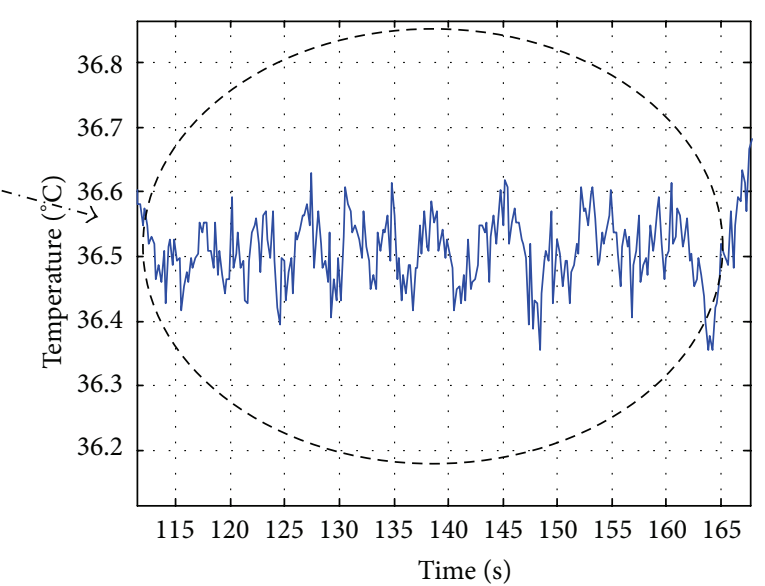

(b)

Figure 18: (a) Temperature characteristic of temperature closed-loop control circuit with start temperature at $31.65^{\circ} \mathrm{C}$. (b) Temperature characteristic partial enlarged detail.

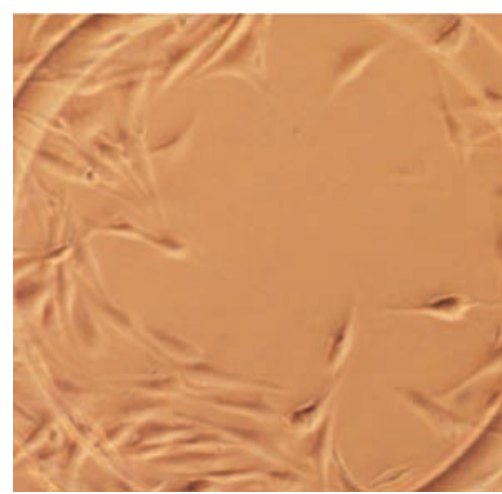

(a)

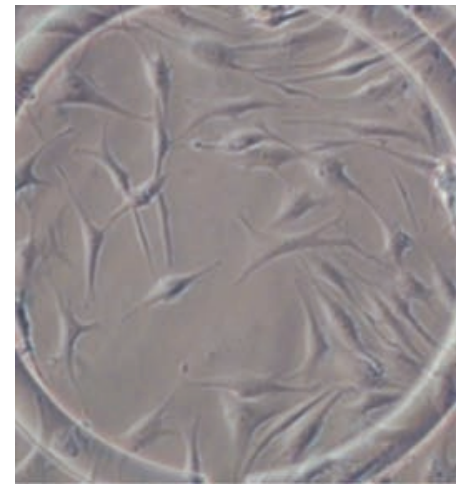

(b)

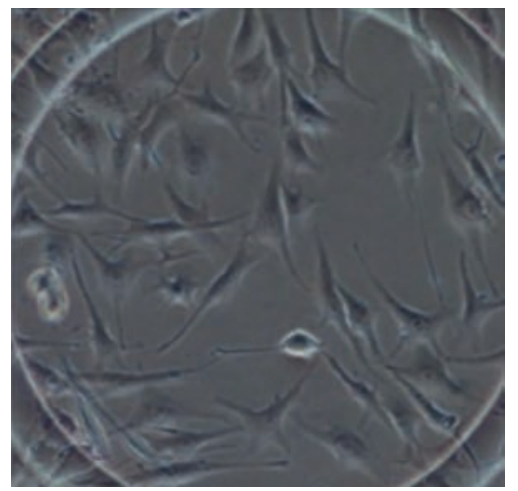

(c)

FIGURE 19: Growth image of M763 cells for different time steps. (a), (b), and (c) are, respectively, growth images of $24 \mathrm{~h}, 48 \mathrm{~h}$, and $72 \mathrm{~h}$.

TABLE 2: The part index of automatic guided space cell culture system.

\begin{tabular}{|c|c|}
\hline Parameter & Index \\
\hline $\begin{array}{l}\text { Microscopic image system } \\
\text { resolution }\end{array}$ & $0.98 \mu \mathrm{m}$ \\
\hline \multirow{2}{*}{ Maximum pixel } & $2048 * 1536$ \\
\hline & $\begin{array}{c}\text { horizontal } \\
C_{x}=138.7 \mathrm{~nm} / \text { pixel; }\end{array}$ \\
\hline Image pixel equivalent & Vertical $C_{y}=139.7 \mathrm{~nm} /$ pixel \\
\hline Frame rate & 5 frame $/ \mathrm{s}$ \\
\hline $\begin{array}{l}\text { Mobile platform } x \text { direction } \\
\text { resolution }\end{array}$ & $0.5 \mu \mathrm{m}$ \\
\hline $\begin{array}{l}\text { Mobile platform } y \text { direction } \\
\text { resolution }\end{array}$ & $0.6 \mu \mathrm{m}$ \\
\hline $\begin{array}{l}\text { Compression rate (for } \\
\text { umbilical vein living cells } \\
\text { image) }\end{array}$ & $39.4: 1$ \\
\hline $\begin{array}{l}\text { Range of recommended } \\
\text { flow-rate }\end{array}$ & $0.3 \mu \mathrm{L} / \mathrm{s} \sim 200 \mu \mathrm{L} / \mathrm{s}$ \\
\hline $\begin{array}{l}\text { Precision of temperature } \\
\text { control }\end{array}$ & $\pm 1^{\circ} \mathrm{C}$ \\
\hline
\end{tabular}


happens. In 72 hours, the process continues. All these indicate that the system design in this paper is successful.

3.2. System Performance. The automatic guided space cell culture system has been calibrated. Part of its performance indexes are as shown in Table 2.

\section{Conclusion}

In this paper, a fused silica space cell culture cavity is designed, simulated, and tested. This culture cavity with circular photic zone for autoobservation and heating coil for adjusting temperature realizes in-place culturing, observing and recording, with the aid of automatic control system having microfluidic and temperature control circuits. The efficacy of the wedge-shaped connection is demonstrated; however, for future space flight mission it should be more robust to perform better leakproofness and be better resistant to the impact of the gravitational acceleration caused by the duration of carrier rocket into orbit. It has also been demonstrated that automatic guided space cell culture system with microfluidic and temperature control circuits is successful in laboratory environment.

The system aims to be used in the future space experiment, and extensive ground testing has been done to verify its functions. It performs perfectly during the test. The only flaw is that the system is too bulky for a space experiment. The future work will focus on the miniaturization of the apparatus.

\section{Acknowledgments}

This work was supported by the Research Program Biological Smart Sensor Technology and Application from the Ministry of Industry and Information Technology of China and by the 863 National High-tech Research and Development Program (2008AA12A20).

\section{References}

[1] B. van der Schoot, M. Boillat, and N. de Rooij, "Micro-instruments for life science research," IEEE Transactions on Instrumentation and Measurement, vol. 50, no. 6, pp. 1538-1542, 2001.

[2] I. Walther, B. van der Schoot, M. Boillat, and A. Cogoli, "Performance of a miniaturized bioreactor in space flight: microtechnology at the service of space biology," Enzyme and Microbial Technology, vol. 27, no. 10, pp. 778-783, 2000.

[3] V. D. Kern, S. Bhattacharya, R. N. Bowman et al., "Life sciences flight hardware are development for the international space station," Advances in Space Research, vol. 27, no. 5, pp. 1023-1030, 2001.

[4] Commercial Generic Bioprocessing Apparatus (CGBA) [EB/ OL], 2009, http://www.nasa.gov/centers/marshall/news/backbackground/facts/cgba.html.

[5] Y. Tan, X. G. Yuan, J. B. Rui, and J. R. Yu, "Research progress of cell culture apparatus," Space Medicine \& Medical Engineering, vol. 15, no. 5, pp. 383-386, 2002.
[6] M. Huang, S. Fan, W. Xing, and C. Liu, "Microfluidic cell culture system studies and computational fluid dynamics," Mathematical and Computer Modelling, vol. 52, no. 11-12, pp. 20362042,2010

[7] N. Hu, X. Zhang, J. Yang, S. W. Joo, and S. Qian, "A cell electrofusion microfluidic chip with micro-cavity microelectrode array," Microfluidics and Nanofluidics, vol. 15, no. 2, pp. 151-160, 2013.

[8] K. Lei, M. H. Wu, P. Y. Liao, Y. M. Chen, and T. M. Pan, "Development of a micro-scale perfusion 3D cell culture biochip with an incorporated electrical impedance measurement scheme for the quantification of cell number in a 3D cell culture construct," Microfluidics and Nanofluidics, vol. 12, no. 1-4, pp. 117-125, 2012.

[9] S. Sharma, A. R. B. Moniz, I. Triantis et al., "An integrated silicon sensor with microfluidic chip for monitoring potassium and pH," Microfluidics and Nanofluidics, vol. 10, no. 5, pp. 1119-1125, 2011.

[10] S. K. Yoo, J. H. Lee, S. S. Yun, M. B. Gu, and J. H. Lee, "Fabrication of a bio-MEMS based cell-chip for toxicity monitoring," Biosensors and Bioelectronics, vol. 22, no. 8, pp. 1586-1592, 2007.

[11] B. S. Elkins, M. Huang, and J. I. Frankel, "Higher-time derivative of in-depth temperature sensors for aerospace heat transfer," International Journal of Thermal Sciences, vol. 52, pp. 31-39, 2012.

[12] F. Vallez-Chetreanu, L. G. Fraisse Ferreira, R. Rabe, U. von Stockar, and I. W. Marison, "An on-line method for the reduction of fouling of spin-filters for animal cell perfusion cultures," Journal of Biotechnology, vol. 130, no. 3, pp. 265-273, 2007.

[13] D. Voisard, F. Meuwly, P. A. Ruffieux, G. Baer, and A. Kadouri, "Potential of cell retention techniques for large-scale highdensity perfusion culture of suspended mammalian cells," Biotechnology and Bioengineering, vol. 82, no. 7, pp. 751-765, 2003.

[14] B. J. Klement and B. S. Spooner, "Utilization of microgravity bioreactors for differentiation of mammalian skeletal tissue," Journal of Cellular Biochemistry, vol. 51, no. 3, pp. 252-256, 1993.

[15] I. Walther, B. van der Schoot, M. Boillat, and A. Cogoli, "Performance of a miniaturized bioreactor in space flight: microtechnology at the service of space biology," Enzyme and Microbial Technology, vol. 27, no. 10, pp. 778-783, 2000.

[16] C. Yi, C. W. Li, S. Ji, and M. Yang, "Microfluidics technology for manipulation and analysis of biological cells," Analytica Chimica Acta, vol. 560, no. 1-2, pp. 1-23, 2006.

[17] J. H. Yeon and J. K. Park, "Microfluidic cell culture systems for cellular analysis," Biochip Journal, vol. 1, no. 1, pp. 17-27, 2007.

[18] J. El-Ali, P. K. Sorger, and K. F. Jensen, "Cells on chips," Nature, vol. 442, no. 7101, pp. 403-411, 2006.

[19] L. Kim, Y. C. Toh, J. Voldman, and H. Yu, "A practical guide to microfluidic perfusion culture of adherent mammalian cells," Lab on a Chip, vol. 7, no. 6, pp. 681-694, 2007.

[20] D. W. Hutmacher and H. Singh, "Computational fluid dynamics for improved bioreactor design and 3D culture," Opinion Trends in Biotechnology, vol. 26, no. 2, pp. 166-172, 2008.

[21] H. Singh, S. H. Teoh, H. T. Low, and D. W. Hutmacher, "Flow modelling within a scaffold under the influence of uni-axial and bi-axial bioreactor rotation," Journal of Biotechnology, vol. 119, no. 2, pp. 181-196, 2005.

[22] W. Xia, S. Fan, W. Xing, C. Liu, T. Li, and J. Wang, "A mathematical morphological approach for region of interest coding of microscopy image compression," Journal of Harbin Institute of Technology, vol. 19, no. 3, pp. 115-121, 2012. 


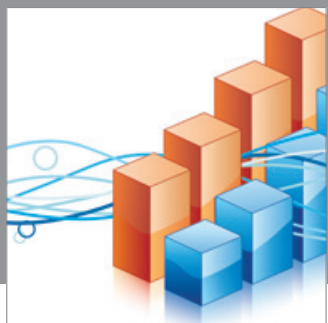

Advances in

Operations Research

mansans

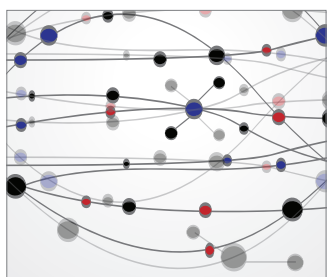

The Scientific World Journal
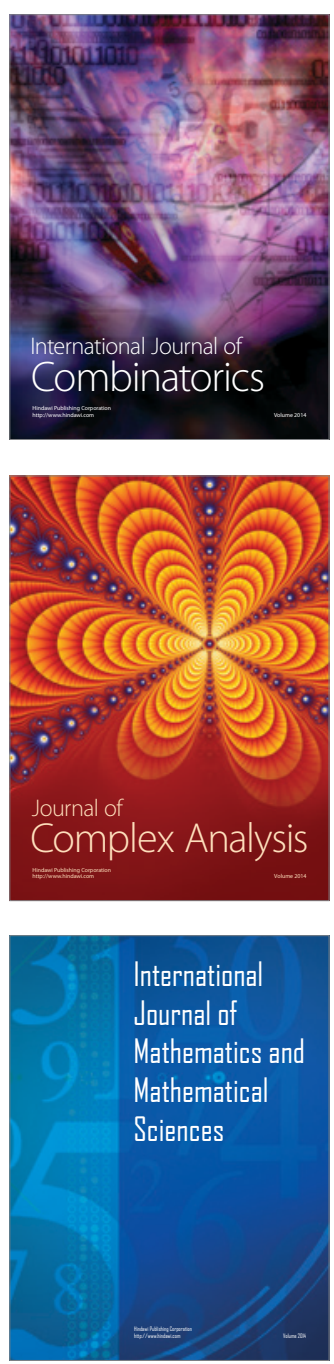
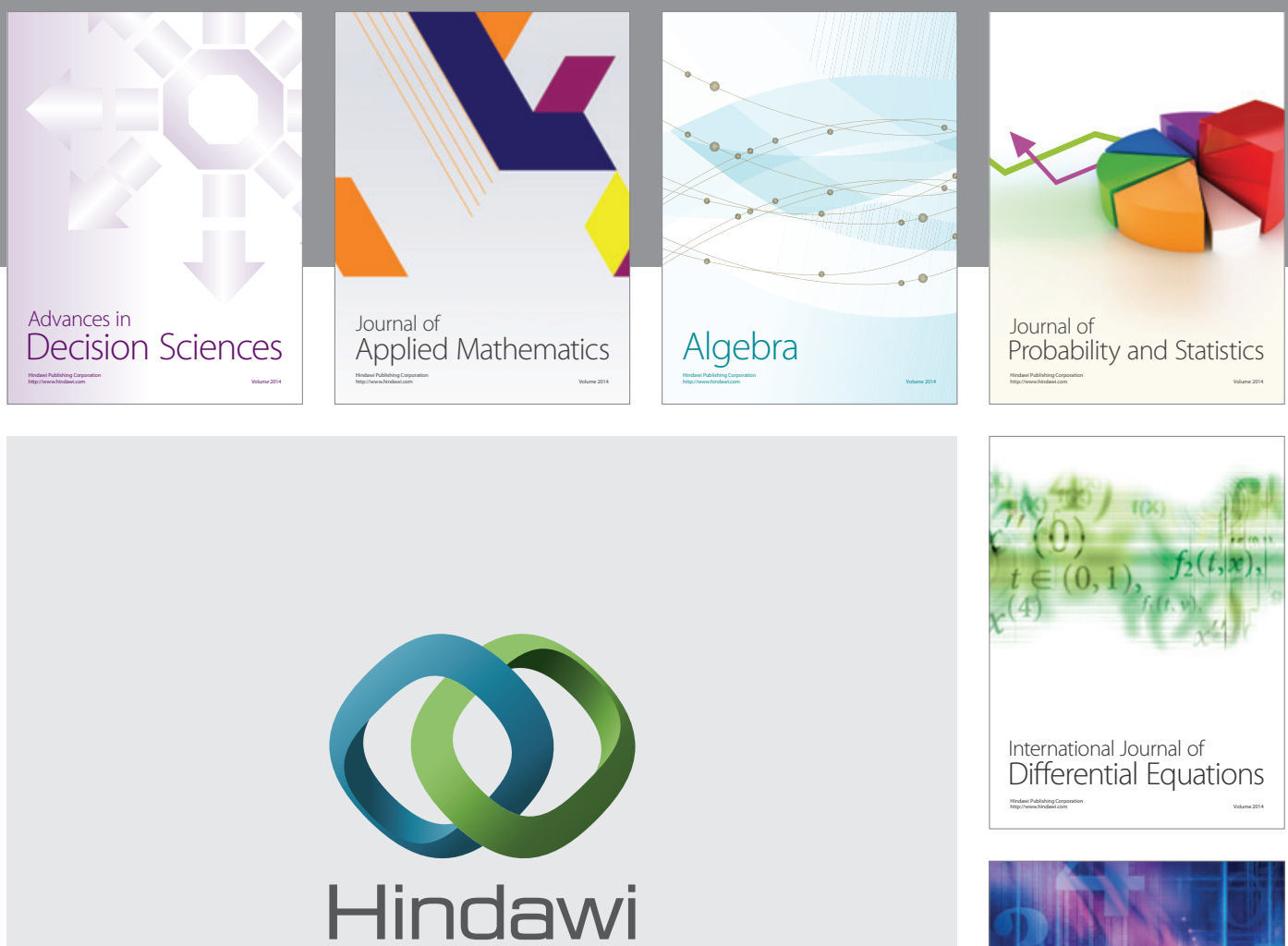

Submit your manuscripts at http://www.hindawi.com
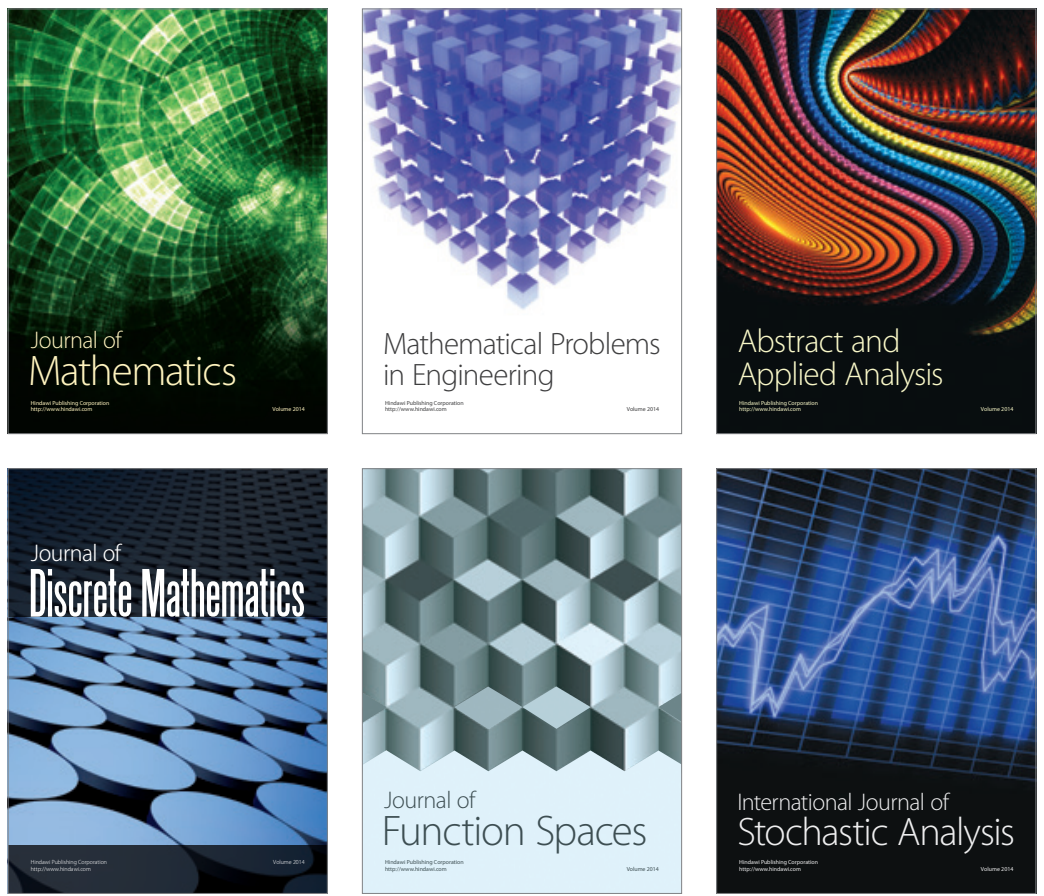

Journal of

Function Spaces

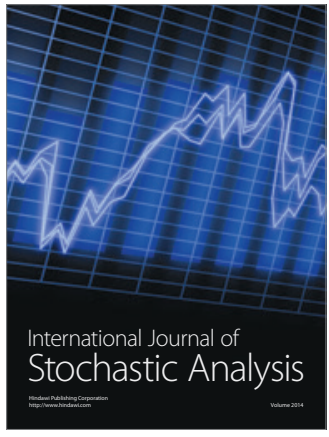

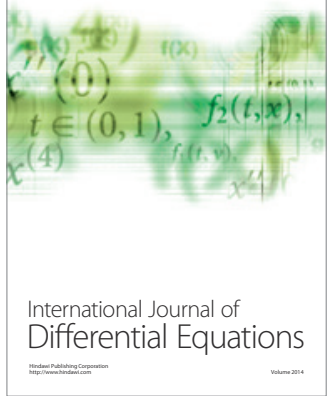
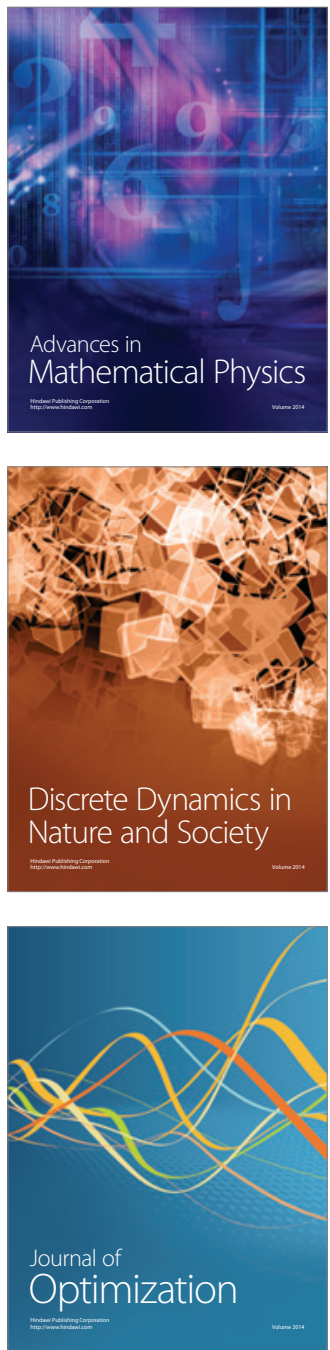